\title{
THE ROLE OF INVASIVE THERAPIES IN ELDERLY PATIENTS WITH ACUTE MYOCARDIAL INFARCTION
}

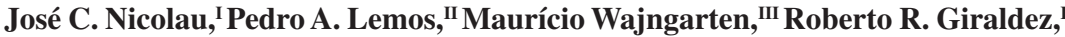 \\ Carlos V. Serrano Jr., Eulógio E. Martinez, ${ }^{\mathrm{II}}$ Luciano M. Baracioli, ${ }^{\mathrm{I}}$ Roberto \\ Kalil, ${ }^{\mathrm{I}}$ Fábio B. Jatene, ${ }^{\text {IV }}$ Luis A. Dallan, ${ }^{\text {IV }}$ Luis B. Puig, ${ }^{\text {IV }}$ Noedir A. Stolf,,${ }^{\text {IV }}$
}

doi: $10.1590 / \mathrm{S1807-59322009000600010}$

\begin{abstract}
Nicolau JC, Lemos PA, Wajngarten M, Giraldez RR, Serrano-Jr. CV, Eulógio E, et al. The role of invasive therapies in elderly patients with acute myocardial infarction. Clinics. 2009;64(6):553-60.
\end{abstract}

INTRODUCTION: In elderly patients with acute myocardial infarction, very little is known about the role of surgical myocardial revascularization and percutaneous coronary intervention (invasive therapies - IT), especially in the context of long-term outcomes after hospital discharge.

METHODS: We analyzed 1588 patients with MI who had been included prospectively in a databank and followed for up to 7.5 years. In this population, 548 patients were $\geq 70$ years old (elderly group - EG), and 1040 were $<70$ years of age (younger group YG); 1088 underwent IT during hospitalization, and the remaining 500 were treated medically (conservative therapy - CT). Patients were monitored either by visit or by phone at least once a year. A standard questionnaire was administered to all patients. The impact of IT was analyzed with both non-adjusted and adjusted models.

RESULTS: By the end of the follow-up period, the survival rates for the IT and CT groups were, respectively, $71.9 \%$ versus $47.2 \%$ in the global population (hazard ratio $=0.55, \mathrm{P}<0.001$ ), $81.5 \%$ versus $66.6 \%$ in the $\mathrm{YG}$ (hazard ratio $=0.68, \mathrm{P}=0.018$ ) and $48.8 \%$ versus $20.3 \%$ in the $\mathrm{EG}$ (hazard ratio $=0.58, \mathrm{P}<0.001)$. In the adjusted models, the hazard ratios were $0.62(\mathrm{P}<0.001)$ in the global population, 0.74 in the $\mathrm{YG}(\mathrm{P}=0.073)$ and $0.64(\mathrm{P}=0.001)$ in the EG.

CONCLUSION: Long-term follow-up of patients with myocardial infarction revealed that IT during the in-hospital phase was at least as effective in elderly patients as in younger patients.

KEYWORDS: Myocardial infarction; Long-term outcome; Elderly population; Coronary artery bypass surgery; Percutaneous coronary intervention.

\section{INTRODUCTION}

An increase in the life expectancy of patients with coronary artery disease (CAD) over the last few decades has

\footnotetext{
I Acute Coronary Disease Unit, Heart Institute (InCor), Hospital das Clínicas da Faculdade de Medicina da Universidade de São Paulo - São Paulo/ SP, Brazil.

II Catheterization Laboratory, Heart Institute (InCor), Hospital das Clínicas da Faculdade de Medicina da Universidade de São Paulo - São Paulo/SP, Brazil.

III Geriatric Cardiology Unit, Heart Institute (InCor), Hospital das Clínicas da Faculdade de Medicina da Universidade de São Paulo - São Paulo/SP, Brazil.

${ }^{\text {Iv }}$ Cardiac Surgery Division, Heart Institute (InCor), Hospital das Clínicas da Faculdade de Medicina da Universidade de São Paulo - São Paulo/SP, Brazil.

E-mail: corjnicolau@incor.usp.br

Tel.: $551130695058 / 5196$

Received for publication on February 06, 2009

Accepted for publication on March 23, 2009
}

led to an increase in the average age of patients hospitalized for acute myocardial infarction (MI). In the USA, about $82 \%$ of patients who die of CAD are aged 65 or older. ${ }^{1}$ On the other hand, despite recent advances, ${ }^{2-6}$ it is well known that both the morbidity and mortality of CAD patients subjected to invasive therapies (ITs - coronary artery bypass surgery or percutaneous coronary intervention) increase with age, and that pre-intervention $\mathrm{MI}$ is an independent risk factor for mortality. ${ }^{7}$ Despite certain data from clinical trials suggesting a greater benefit of IT in elderly patients with acute coronary syndromes, ${ }^{8 ; 9}$ the applicability of findings from trials that enrolled predominantly younger patients to an older and generally less healthy population is questionable. ${ }^{10}$

Specifically in the context of MI, it has been demonstrated that IT utilization is influenced by racial and socioeconomic factors, ${ }^{11 ; 12}$ and that IT is underused 
in the elderly population. ${ }^{13}$ Likely reasons for this include practitioner concerns about the increased risk of complications, ${ }^{14}$ patient heterogeneity, atypical presentation, and limited representation in clinical trials. ${ }^{15}$ However, very few published studies have addressed the impact of IT on long-term outcome after MI, ${ }^{16 ; 17}$ with no data, to our knowledge ${ }^{14 ; 15}$, specifically addressing the case of elderly patients. Therefore, the main objective of this study was to analyze, in patients with acute myocardial infarction, the impact of IT on long-term outcome, with a special focus on the elderly.

\section{METHODS}

From an initial population of 1623 patients with MI included prospectively in a dedicated databank between $01 / 1998$ and $01 / 2005$, we analyzed 1588 patients [mean age $63.26 \pm 12.9$ y (range 10 to $98 \mathrm{y}$ ), $71.7 \%$ men] who were followed for up to 7.5 years (mean survival time $=5.65$ years). Thirty-five patients (20 in the invasive and 15 in the conservative group, $2.2 \%$ from the initial population) were lost to follow-up and excluded from the present report. In the invasive group (1086 pts, since we received only vital signs data in 2 cases), after the index hospitalization 75 pts (6.9\%) were submitted to percutaneous coronary intervention (PCI) and $34(3.13 \%)$ to coronary artery bypass surgery (CABG). In the conservative group (499 pts, since in one case we received only vital signs data), after the index hospitalization $29(5.8 \%)$ were submitted to PCI and $4.4 \%$ to CABG.

In the population we studied, 548 patients were $\geq 70$ years old (elderly group - EG), and the remaining 1040 patients were $<70$ years old (younger group - YG). In addition, of the 1588 patients, 1088 underwent IT during hospitalization (519 non-primary PCI, 344 primary PCI, 272 CABG, 47 both therapeutic modalities - none was submitted to the 3 procedures). The remaining 500 patients comprised the group that did not undergo IT during hospitalization (conservative group, CT). In the elderly population, 334 (60.9\%) patients underwent IT and 214 (39.1\%) patients underwent CT. Within the YG, 754 (72.5\%) underwent IT and $286(27.5 \%)$ underwent CT.

Follow-up was performed by personal contact or by phone at least once a year, and patients submitted a questionnaire with information about their outcome after hospital discharge. Definitions and therapies utilized during the hospitalization period followed internal institutional guidelines, based on recommendations from the Brazilian, European and North-American Societies of Cardiology. In the long-run, patients were followed by his/her physician, meaning that no standardized therapeutic routine of followup was implemented.
Statistical analyses: Characteristics of the global population, EG and YG groups were compared using Pearson chi-square tests or Fisher exact tests as appropriate. KaplanMeier estimates of survival in the global population, EG and YG were determined and statistically evaluated using the log-rank test. Interaction tests between age (as a continuous variable) and therapeutic strategy with regard to mortality were developed for the whole population, the EG and the YG. The Stepwise Cox proportional hazards regression model was used in the adjusted models. The thresholds for each step were 0.05 for entry and 0.10 for removal; all-cause mortality was the dependent variable, and the candidates for independent predictors were: history of MI, previous percutaneous coronary intervention or coronary artery bypass graft, heart failure, diabetes mellitus, stroke, arterial hypertension, hypercholesterolemia, smoking, family history of coronary artery disease, type of MI (ST elevation or nonST elevation), MI location (anterior wall or other), gender, conservative/invasive treatment during hospitalization and fibrinolytic utilization. SPSS 13.0 software was utilized for the calculations.

\section{RESULTS}

The number of patients from the study population submitted to coronary angiography was 1417 (89.2\%), with $452(82.5 \%)$ of these from the EG and 965 (92.8\%) from the YG $(\mathrm{P}<0.001,95 \% \mathrm{CI}$ of the difference 13.5 to 7.08$)$. Invasive therapies were utilized in $334(60.9 \%)$ patients from the EG and $754(72.5 \%)$ patients from the YG $(\mathrm{P}<0.001$, $95 \%$ CI 6.79 to 16.4$)$.

Univariate comparisons between the conservative and invasive groups in the global population, in the elderly group and in the younger group are listed in Tables 1, 2 and 3 , respectively. As can be seen, CT patients exhibited higher incidences of previous MI, revascularization surgery and heart failure, and IT patients were more likely to be male, smokers, and to have hypercholesterolemia, ST-elevation MI, anterior wall MI and a family history of CAD.

Figures 1, 2 and 3 show the estimated survival rates of all the patients, the YG patients and the EG patients, respectively. As can be noticed, patients who underwent IT during hospitalization exhibited better outcomes than those treated medically. The hazard-ratio and P-values seem to suggest a more impressive benefit in the older group, but no formal interaction between age and IT benefit in the whole population was observed. Moreover, the curves diverge earlier in the elderly group - suggesting an earlier benefit in these patients. Figure 4 shows the estimated mean survival times of the CT and IT groups for each of the analyzed populations. Including in-hospital deaths, the 
Table 1 - Comparison of conservative and invasive therapy in the global population

\begin{tabular}{lcccc}
\hline Variables & Cons. Group (N=500) & Inv. Group (N=1088) & P-value & Odds-ratio (95\% CI) \\
\hline Hx MI (\%) & 33.4 & 26.7 & 0.006 & $0.72(0.58$ to 0.91$)$ \\
Hx PCI (\%) & 11.6 & 11.6 & 0.991 & $1.0(0.72$ to 1.39$)$ \\
Hx CABG (\%) & 17.6 & 11.8 & 0.002 & $0.62(0.46$ to 0.84$)$ \\
Hx HF (\%) & 12.0 & 5.2 & $<0.001$ & $0.41(0.28$ to 0.60$)$ \\
Hx DM (\%) & 26.4 & 27.7 & 0.599 & $1.07(0.84$ to 1.36$)$ \\
Hx stroke (\%) & 3.4 & 3.7 & 0.783 & $1.08(0.61$ to 1.93$)$ \\
Hx hypertension (\%) & 67.8 & 65.4 & 0.356 & $0.90(0.72$ to 1.13$)$ \\
Family Hx of CAD (\%) & 21.2 & 29.0 & 0.001 & $1.52(1.18$ to 1.96$)$ \\
Hx hypercholesterolemia (\%) & 39.2 & 49.3 & $<0.001$ & $1.51(1.21$ to 1.87$)$ \\
Hx smoking (\%) & 23.6 & 31.0 & 0.003 & $1.45(1.14$ to 1.85$)$ \\
ST-elevation MI (\%) & 39.8 & 62.7 & $<0.001$ & $2.54(2.04$ to 3.17$)$ \\
Anterior MI (\%) & 37.0 & 44.9 & 0.003 & $1.39(1.12$ to 1.73$)$ \\
Fibrinolytic (\%) & 20.0 & 21.5 & 0.494 & $1.09(0.84$ to 1.42$)$ \\
Men (\%) & 66.4 & 74.1 & 0.002 & $1.45(1.15$ to 1.82$)$ \\
\hline
\end{tabular}

Cons.=conservative; Inv.=invasive; $\mathrm{CI}=$ confidence interval; $\mathrm{Hx}=$ history of; $\mathrm{MI}=$ myocardial infarction; $\mathrm{PCI}=$ percutaneous coronary intervention; $\mathrm{CABG}=$ coronary artery bypass graft; $\mathrm{HF}=$ heart failure; $\mathrm{DM}=$ diabetes mellitus; $\mathrm{CAD}=$ coronary artery disease.

Table 2 - Comparison of conservative and invasive therapy in elderly patients

\begin{tabular}{lcccc}
\hline Variables & Cons. Group (N=214) & Inv. Group (N=334) & P-value & Odds-ratio (95\% CI) \\
Hx MI (\%) & 39.3 & 28.4 & 0.008 & $0.62(0.43$ to 0.88$)$ \\
Hx PCI (\%) & 12.1 & 12.3 & 0.965 & $1.01(0.60$ to 1.71$)$ \\
Hx CABG (\%) & 19.6 & 17.4 & 0.504 & $0.86(0.55$ to 1.34$)$ \\
Hx HF (\%) & 17.8 & 7.5 & $<0.001$ & $0.38(0.22$ to 0.64$)$ \\
Hx DM (\%) & 29.4 & 29.9 & 0.900 & $1.02(0.70$ to 1.49$)$ \\
Hx stroke (\%) & 4.2 & 5.7 & 0.442 & $1.37(0.61$ to 3.09$)$ \\
Hx hypertension (\%) & 74.8 & 65.6 & 0.023 & $0.64(0.44$ to 0.94$)$ \\
Family Hx CAD (\%) & 14.0 & 20.1 & 0.071 & $1.54(0.96$ to 2.46$)$ \\
Hx hypercholesterolemia (\%) & 37.4 & 11.4 & 0.162 & $1.28(0.90$ to 1.83$)$ \\
Hx smoking (\%) & 8.9 & 57.5 & 0.350 & $1.32(0.74$ to 2.35$)$ \\
ST-elevation MI (\%) & 34.7 & 46.4 & $<0.001$ & $2.65(1.85$ to 3.78$)$ \\
Anterior MI (\%) & 36.4 & 12.6 & 0.021 & $1.51(1.06$ to 2.15$)$ \\
Fibrinolytic $(\%)$ & 11.7 & 63.2 & 0.756 & $1.09(0.64$ to 1.84$)$ \\
Men (\%) & 60.7 & 0.568 & $1.11(0.78$ to 1.58$)$ \\
\hline
\end{tabular}

Legend as for Table 1

CT and IT survival times in the global population were, respectively: 1819 (95\% CI 1710 to 1928$)$ vs. 2188 (95\% CI 2121 to 2254) days; in the YG they were 2214 (95\% CI 2093 to 2335) vs. 2378 (95\% CI 2310 to 2446) days; and in the EG they were 1267 (95\% CI 1101 to 1434) vs. 1753 (95\% CI 1612 to 1894) days. Excluding in-hospital deaths, the CT and IT survival times in the global population were, respectively: 2083 (95\% CI 1979 to 2188) vs. 2420 (95\% CI 2363 to 2471) days; in the YG they were 2349 (95\% CI 2239 to 2460 ) vs. 2506 (95\% CI 2448 to 2565) days; and in the
EG they were 1620 (95\% CI 1437 to 1803) vs. 2181 (95\% CI 2046 to 2315) days. Testing for interactions between the effects of age and treatment strategy on death rates yielded a P-value of 0.783 for the whole population, 0.125 for the younger group, and 0.893 for the elderly group.

The average durations of the index hospitalization stays were $15.1 \pm 14.7$ days for the EG and $12.5 \pm 13.3$ days for the $\mathrm{YG}(\mathrm{P}=0.001,95 \% \mathrm{CI} 1.13$ to 4.15$)$. For patients submitted to IT, there were no significant survival differences between primary angioplasty, non-primary angioplasty and 
Table 3 - Comparison of conservative and invasive therapy in younger patients

\begin{tabular}{lcccc}
\hline Variables & Cons. Group (N=286) & Inv. Group (N=754) & P-value & Odds-ratio (95\% CI) \\
\hline Hx MI (\%) & 29.0 & 25.9 & 0.304 & $0.85(0.63$ to 1.15$)$ \\
Hx PCI (\%) & 11.2 & 11.3 & 0.969 & $1.0(0.65$ to 1.55$)$ \\
Hx CABG (\%) & 16.1 & 9.3 & 0.002 & $0.53(0.36$ to 0.78$)$ \\
Hx HF (\%) & 7.7 & 4.2 & 0.025 & $0.53(0.30$ to 0.93$)$ \\
Hx DM (\%) & 24.1 & 26.7 & 0.406 & $1.14(0.83$ to 1.57$)$ \\
Hx stroke (\%) & 2.8 & 2.8 & 0.992 & $1.0(0.47$ to 2.27$)$ \\
Hx hypertension (\%) & 62.2 & 65.4 & 0.400 & $1.13(0.85$ to 1.50$)$ \\
Family Hx CAD (\%) & 26.6 & 32.9 & 0.049 & $1.35(1.00$ to 1.83$)$ \\
Hx hypercholesterolemia (\%) & 51.9 & 0.001 & $1.58(1.20$ to 2.08$)$ \\
Hx smoking (\%) & 40.6 & 39.7 & 0.135 & $1.24(0.93$ to 1.65$)$ \\
ST-elevation MI (\%) & 34.6 & 64.6 & $<0.001$ & $2.33(1.76$ to 3.10$)$ \\
Anterior MI (\%) & 43.9 & 44.3 & 0.045 & $1.33(1.01$ to 1.76$)$ \\
Fibrinolytic (\%) & 37.4 & 25.5 & 0.802 & $1.96(0.71$ to 1.31$)$ \\
Men (\%) & 26.2 & 78.9 & 0.005 & $1.56(1.14$ to 2.12$)$ \\
\hline
\end{tabular}

Legend as for Table 1

Table 4 - Non-adjusted and adjusted hazard ratios for invasive and conservative treatment in the global population, and in younger and elderly groups

\begin{tabular}{lcccccc}
\hline Groups & Non-adjusted HR & $95 \%$ CI & P-value & Adjusted HR & $95 \%$ CI & P-value \\
\hline Global & 0.55 & $0.45-0.67$ & $<0.001$ & 0.62 & $0.51-0.77$ & $<0.001$ \\
Younger & 0.68 & $0.49-0.94$ & 0.018 & 0.74 & $0.53-1.03$ & 0.073 \\
Elderly & 0.58 & $0.45-0.75$ & $<0.001$ & 0.64 & $0.49-0.83$ & 0.001 \\
\hline
\end{tabular}

Global population

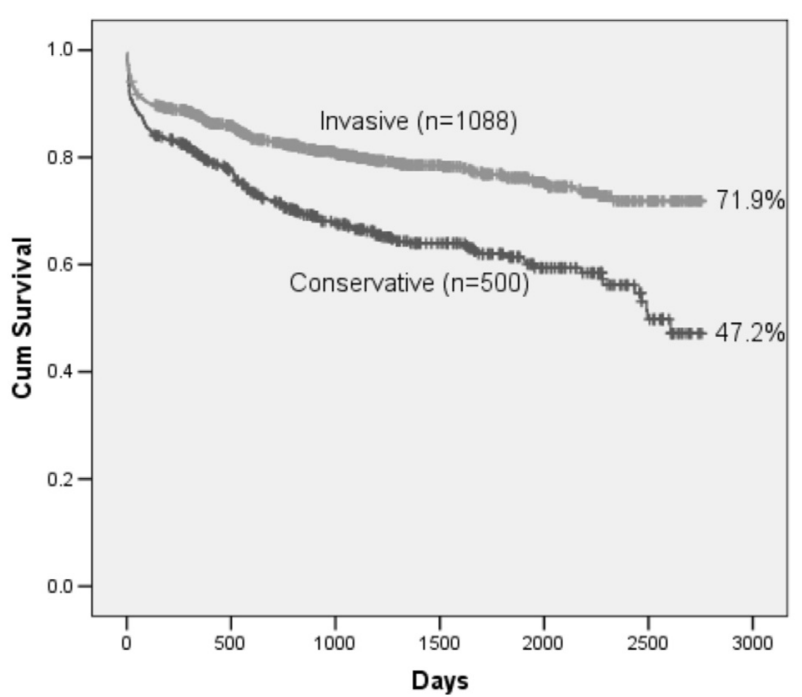

Figure 1 - Cumulative survival rates for the global population (Hazard ratio $0.55, \mathrm{P}<0.001)$
Younger population

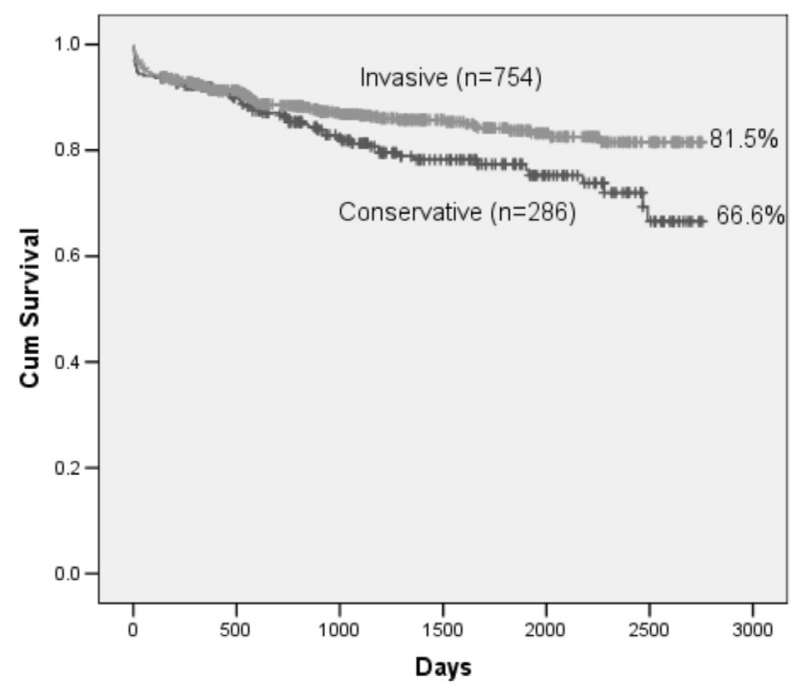

Figure 2 - Cumulative survival rates for the younger population (Hazard ratio $0.68, \mathrm{P}=0.018$ ) 


\section{Elderly population}

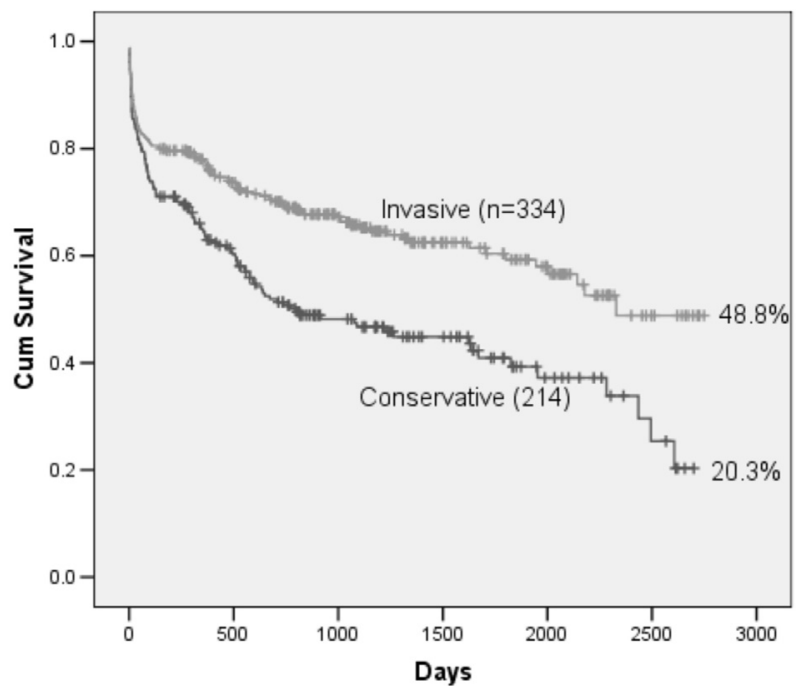

Figure 3 - Cumulative survival rates for the elderly population (Hazard ratio $0.58, \mathrm{P}<0.001$ )

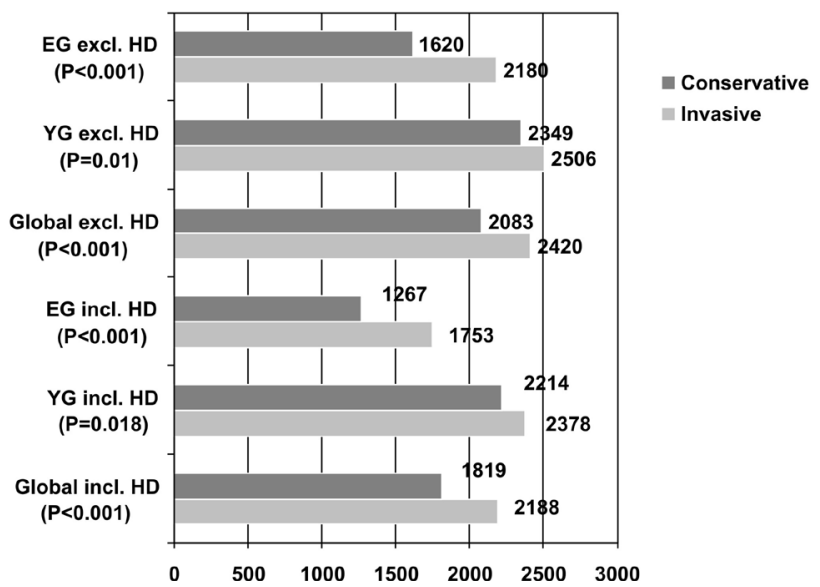

Figure 4 - Estimated mean survival time (days) including (incl.) or excluding (excl.) in-hospital deaths (HD) for the global population, younger group (YG) and elderly group (EG). The 95\% confidence intervals for each group are listed in the text.

surgical revascularization; the estimated mean survival times were, respectively, 1476 (95\% CI 1245 to 1706) days, 1795 (95\% CI 1590 to 2000) days and 1833 (95\% CI 1566 to 2100) days for the EG ( $\mathrm{P}=0.160)$, and 2238 (95\% CI 2099 to 2378 ) days, 2392 (95\% CI 2296 to 2488) days and 2399 (95\% CI 2310 to 2446) days for the YG (P=0.595). In the long run, the outcomes for patients with ST-elevation and non-ST-elevation MI were similar: for the EG, the estimated mean survival times were, respectively, 1711 (95\% CI 1526 to 1897 ) vs. 1811 (95\% CI 1592 to 2030) days for patients submitted to IT $(\mathrm{P}=0.373)$ and 1254 (95\% CI 990 to 1518) vs. 1265 (95\% CI 1047 to 1483) days for those treated conservatively ( $\mathrm{P}=0.946)$; for the $\mathrm{YG}$, the figures were 2389 (95\% CI 2307 to 2471$)$ vs. 2354 (95\% CI 2235 to 2474 ) days for patients submitted to IT $(\mathrm{P}=0.757)$ and $2200(95 \%$ CI 2020 to 2381) vs. 2168 (95\% CI 1992 to 2344) days for those treated conservatively $(\mathrm{P}=0.540)$.

In the adjusted models, IT correlated significantly, independently and inversely with long-term mortality in the elderly group (hazard ratio=0.64, $\mathrm{P}=0.001$ ), but the hazard ratio obtained for the $\mathrm{YG}$ did not reach statistical significance (hazard ratio $=0.74, \mathrm{P}=0.073$ ), as shown in Table 4. Other variables that correlated significantly and independently with mortality in the adjusted models were: in the global population, fibrinolytic utilization $(\mathrm{HR}=0.62$, $\mathrm{P}=0.001)$; previous history of stroke $(\mathrm{HR}=2.06, \mathrm{P}<0.001)$, hypercholesterolemia $(\mathrm{HR}=0.60, \mathrm{P}<0.001)$, diabetes $(\mathrm{HR}=1.38, \mathrm{P}=0.003)$, relatives with $\mathrm{CAD}(\mathrm{HR}=0.67$, $\mathrm{P}=0.003)$, smoking ( $\mathrm{HR}=0.71, \mathrm{P}=0.009)$, MI $(\mathrm{HR}=1.32$, $\mathrm{P}=0.018)$ and heart failure $(\mathrm{HR}=2.28, \mathrm{P}<0.001)$; in the $\mathrm{YG}$, history of stroke $(\mathrm{HR}=2.12, \mathrm{P}=0.017)$, hypercholesterolemia $(\mathrm{HR}=0.68, \mathrm{P}=0.019)$, diabetes $(\mathrm{HR}=1.83, \mathrm{P}<0.001)$, MI $(\mathrm{HR}=1.49, \mathrm{P}=0.022)$, and heart failure $(\mathrm{HR}=3.38, \mathrm{P}<0.001)$; and in the $\mathrm{EG}$, history of angioplasty $(\mathrm{HR}=0.51, \mathrm{P}=0.007)$, stroke (HR=2.45, $\mathrm{P}=0.001)$, hypercholesterolemia $(\mathrm{HR}=0.59$, $\mathrm{P}<0.001)$, and heart failure $(\mathrm{HR}=1.73, \mathrm{P}=0.004)$.

In our institution, especially during more recent years, patients with ST-elevation MI receive primary PCI within 12 hours of evolution on a routine basis. Therefore, for this subset, the conservative approach was almost never applied in practice. Because of this, adjusted models were developed excluding these patients, and showed that the IT group continued to fare significantly better than the conservative group: for the global population, the adjusted hazard ratio was $0.58(\mathrm{P}<0.001)$, for the $\mathrm{EG}$ it was $0.50(\mathrm{P}<0.001)$, and for the $\mathrm{YG}$ it was $0.70(\mathrm{P}=0.056)$.

In order to avoid a possible early survival bias (i.e., patients have to live long enough to undergo an invasive procedure, causing IT to become a marker for early survival), Kaplan-Meier curves were constructed excluding in-hospital deaths. At the end of the follow-up, the following survival rates were obtained: in the global population $(n=1417)$, $54.4 \% \pm 5.3$ and $79.9 \% \pm 2.2$ respectively for the CT $(\mathrm{n}=435)$ and IT $(\mathrm{n}=982)$ groups $(\mathrm{HR}=0.45, \mathrm{P}<0.001)$; in the EG $(n=433), 26.3 \% \pm 8.9$ and $61.5 \% \pm 8.6$ respectively for the CT $(n=166)$ and IT $(n=267)$ groups $(H R=0.41$, $\mathrm{P}<0.001)$; and in the $\mathrm{YG}(\mathrm{n}=984), 71.0 \% \pm 5.3$ and $86.1 \% \pm$ 2.0 respectively for the $\mathrm{CT}(\mathrm{n}=269)$ and IT $(\mathrm{n}=715)$ groups ( $\mathrm{HR}=0.60, \mathrm{P}=0.01)$. In the adjusted models, the following hazard ratios were obtained: for the global population, 0.50 $(\mathrm{P}<0.001)$; for the EG, $0.44(\mathrm{P}<0.001)$; and for the $\mathrm{YG}, 0.63$ $(\mathrm{P}=0.024)$. Tests for interactions between the effects of age and treatment strategy on death rates showed P-values of $0.714,0.002$ and 0.69 in the whole population, $\mathrm{YG}$, and EG, respectively. 


\section{DISCUSSION}

The underutilization of invasive therapies in the elderly: Many studies have unequivocally shown that invasive therapies are underutilized in the elderly. ${ }^{13} \mathrm{MI}$ patients who are older appear to wait the longest before seeking medical attention. ${ }^{18}$ Furthermore, IT is associated with higher morbidity and mortality rates in this population than in younger people, leading to longer hospital stays, and likely influencing the assisting physician to be more conservative with these patients. In our study population these tendencies were confirmed: IT was utilized less in older patients $(60.9 \%$ and $72.5 \%$ in the EG and $\mathrm{YG}$, respectively), the long-term survival rates were $48.9 \%$ and $81.5 \%$, respectively, and the hospitalization stays were, respectively, 15.1 and 12.5 days. In fact, some authors have proposed a convalescence cardiac unit for older patients as a transitional facility from hospital to home, ${ }^{19}$ and the optimal rate of invasive therapies is a frequent topic of discussion. ${ }^{20}$

Differences between the elderly and younger groups: The data in Table 1 indicate that, in the global population, certain variables had different incidence rates in the IT and CT groups. These included previous heart failure (smaller incidence in the IT group) and ST-elevation MI and anterior MI location (higher incidences in the IT group). However, the variables associated with the IT and CT groups differed somewhat when the younger (Table 3) and older (Table 2) patients were considered separately. Arterial hypertension and previous MI were more frequent in elderly IT patients than in elderly CT patients, while the incidence rates of these variables were similar between the younger IT and CT patients. However, in younger patients (but not in older patients) there were different incidence rates of previous revascularization surgery, relatives with CAD and hypercholesterolemia in the IT and CT groups. There was a higher incidence of males in the IT group only among younger patients, and this was likely due to the higher proportion of women with MI in the elderly population. ${ }^{1}$

The role of IT in elderly and younger patients: In the TACTICS-TIMI 18 study that analyzed 2220 patients with non-ST elevation ACS, the significant benefit in the composite endpoint (6-month mortality, nonfatal MI, rehospitalization, stroke, and hemorrhagic complications) demonstrated for the invasive approach was restricted to elderly patients (65 years-old or older), while the invasive and conservative approaches yielded similar results in the younger population. ${ }^{8}$ It is important to note, in that study, that the mortality rates were similar for the invasive and conservative groups $(1.8 \%$ and $1.7 \%$ respectively for younger people, $5.3 \%$ and $5.9 \%$ respectively for the elderly population). Moreover, as pointed out by the authors, the generalizability of the results for elderly patients without the excluded comorbid conditions remain unknown. Probably the most feared complication in elderly people is bleeding. In the GRACE Registry, the investigators observed that $10 \%$ of all hospital deaths were related to major bleeding, and the incidence of this complication was clearly correlated with age..$^{21}$ On the other hand, the CRUSADE Registry demonstrated that, in patients over 89 years old, the higher risk of bleeding related to invasive therapies is outweighed by the obtained benefit. ${ }^{22}$ Recently it has been shown that people 80 years and older who receive drug-eluting stents are more likely to die in the year following stent implantation than younger patients, but they are no more likely to require repeat revascularization procedures. After adjusting for age and sex, the life expectancy of the DES-treated octogenarians was similar to that of the general population, despite the fact that older subjects tended to be sicker at the time of stenting. ${ }^{23}$

On the other hand, primary PCI was shown to be highly effective in patients with ST-elevation MI. ${ }^{24}$ In our study, which included MI patients both with and without ST elevation, the benefit of invasive therapies was maintained even when patients submitted to primary PCI were excluded from the analyses. Moreover, taking into account long-term survival and excluding in-hospital deaths, a significant correlation between age and invasive therapy was found in the YG but not in the EG, suggesting that the impact of age on long-term results is more pronounced in younger patients.

Limitations of the study: The main limitation of the study is the fact that patients were not allocated to IT and CT groups in a randomized manner. In addition, the reasons for not submitting certain patients to invasive therapies were not retrievable from the databank. On the other hand, this study accurately depicts treatment realities in a high-volume, tertiary cardiology hospital. Moreover, there is little evidence that estimates of treatment effects in observational studies are either consistently larger than or qualitatively different from those obtained in randomized controlled trials. ${ }^{25}$ Another limitation is that characteristics specific to our hospital and its patient population may limit how generalizable our results are to hospitals and regions dissimilar to ours. ${ }^{11 ; 12 ; 26} \mathrm{~A}$ third possible limitation is the fact that the analyzed population was not treated with the same protocol after hospital discharge, since this treatment was left to the discretion of the attending physician. Moreover, a transdisciplinary approach to the follow-up could improve the general results. ${ }^{27}$ However, since this approach is widely utilized, even in randomized trials, ${ }^{28}$ we believe that this fact did not confound our results. 
In conclusion, in the long-term after myocardial infarction, invasive therapies utilized during the in-hospital phase are at least as efficacious in elderly patients as in younger patients.

\section{ACKNOWLEDGEMENTS}

The authors are indebted to Drs. Christopher Granger and Kenneth Mahaffey for their input on the manuscript.

\section{REFERENCE}

1. Heart Disease and Stroke Statistics. www.americanheart.org. 2008. Ref Type: Internet Communication

2. Rodriguez R, Torrents A, Garcia P. [Cardiac surgery in elderly patients]. Rev Esp Cardiol. 2002;55:1159-68.

3. Ferguson TB, Jr., Coombs LP, Peterson ED. Preoperative beta-blocker use and mortality and morbidity following CABG surgery in North America. JAMA. 2002;287:2221-7.

4. Fein SA, Breisblatt W, Doyle JT, Singh A. Approach to ischemic heart disease, coronary care, and severe heart failure (including cardiogenic shock). Clin Geriatr Med. 1994;10:145-60.

5. Wennberg DE, Makenka DJ, Sengupta A. Percutaneous transluminal coronary angioplasty in the elderly: epidemiology, clinical risk factors, and in-hospital outcomes. The Northern New England Cardiovascular Disease Study Group. Am Heart J. 1999;137:639-45.

6. Haan CK, O'Brien S, Edwards FH, Peterson ED, Ferguson TB. Trends in emergency coronary artery bypass grafting after percutaneous coronary intervention, 1994-2003. Ann Thorac Surg. 2006;81:1658-65.

7. Kolh P, Kerzmann A, Lahaye L, Gerard P, Limet R. Cardiac surgery in octogenarians; peri-operative outcome and long-term results. Eur Heart J. 2001;22:1235-43.

8. Bach RG, Cannon CP, Weintraub WS. The effect of routine, early invasive management on outcome for elderly patients with nonST-segment elevation acute coronary syndromes. Ann Intern Med. 2004;141:186-95.

9. Lagerqvist B, Husted S, Kontny F, Stahle E, Swahn E, Wallentin L. 5 -year outcomes in the FRISC-II randomised trial of an invasive versus a non-invasive strategy in non-ST-elevation acute coronary syndrome: a follow-up study. Lancet. 2006;368:998-1004.
10. Bassand JP, Hamm CW, Ardissino D. Guidelines for the diagnosis and treatment of non-ST-segment elevation acute coronary syndromes. Eur Heart J. 2007;28:1598-660.

11. Fang J, Alderman MH. Is geography destiny for patients in New York with myocardial infarction? Am J Med. 2003;115:448-53.

12. Gregory PM, Malka ES, Kostis JB, Wilson AC, Arora JK, Rhoads GG. Impact of geographic proximity to cardiac revascularization services on service utilization. Med Care. 2000;38:45-57.

13. Bhatt DL, Roe MT, Peterson ED. Utilization of early invasive management strategies for high-risk patients with non-ST-segment elevation acute coronary syndromes: results from the CRUSADE Quality Improvement Initiative. JAMA. 2004;292:2096-104.

14. Alexander KP, Newby LK, Cannon CP. Acute coronary care in the elderly, part I: Non-ST-segment-elevation acute coronary syndromes: a scientific statement for healthcare professionals from the American Heart Association Council on Clinical Cardiology: in collaboration with the Society of Geriatric Cardiology. Circulation. 2007;115:2549-69.

15. Alexander KP, Newby LK, Armstrong PW. Acute coronary care in the elderly, part II: ST-segment-elevation myocardial infarction: a scientific statement for healthcare professionals from the American Heart Association Council on Clinical Cardiology: in collaboration with the Society of Geriatric Cardiology. Circulation. 2007;115:2570-89.

16. Nicolau JC, Ardito RV, Garzon SA. Surgical revascularization after fibrinolysis in acute myocardial infarction. Long-term follow-up. J Thorac Cardiovasc Surg. 1994;107:1454-9.

17. Nicolau JC, Marin-Neto JA, Giraldez RR, Golin V, Rabelo A, Jr., Ramires JA. A comparison of percutaneous coronary intervention and surgical revascularization after fibrinolysis for acute myocardial infarction. Insights from the InTIME-2 trial. Int J Cardiol. 2007;116:3838 . 
18. Ting HH, Bradley EH, Wang Y. Factors associated with longer time from symptom onset to hospital presentation for patients with ST-elevation myocardial infarction. Arch Intern Med. 2008;168:959-68.

19. Lubart E, Leibovitz A, Berkman P, Baumohl Y, Habot B. Preliminary evaluation of a convalescence cardiac unit for older patients as a model of "transitional facility" from hospital to home. J Am Med Dir Assoc. $2001 ; 2: 302-4$

20. Tu JV, Naylor CD, Kumar D, DeBuono BA, McNeil BJ, Hannan EL. Coronary artery bypass graft surgery in Ontario and New York State: which rate is right? Steering Committee of the Cardiac Care Network of Ontario. Ann Intern Med. 1997;126:13-9.

21. Spencer FA, Moscucci M, Granger CB. Does comorbidity account for the excess mortality in patients with major bleeding in acute myocardial infarction? Circulation. 2007;116:2793-801.

22. Skolnick AH, Alexander KP, Chen AY. Characteristics, management, and outcomes of 5,557 patients age $>$ or $=90$ years with acute coronary syndromes: results from the CRUSADE Initiative. J Am Coll Cardiol. 2007;49:1790-7.
23. Vlaar PJ, Lennon RJ, Rihal CS. Drug-eluting stents in octogenarians: early and intermediate outcome. Am Heart J. 2008;155:680-6.

24. Keeley EC, Boura JA, Grines CL. Primary angioplasty versus intravenous thrombolytic therapy for acute myocardial infarction: a quantitative review of 23 randomised trials. Lancet. 2003;361:13-20.

25. Benson K, Hartz AJ. A comparison of observational studies and randomized, controlled trials. N Engl J Med. 2000;342:1878-86.

26. Cram P, Rosenthal GE, Vaughan-Sarrazin MS. Cardiac revascularization in specialty and general hospitals. N Engl J Med. 2005;352:1454-62.

27. Costa e Silva R, Pellanda L, Portal V, Maciel P, Furquim A, Schaan B.Transdisciplinary approach to the follow-up of patients after myocardial infarction. Clinics. 2008;63(4):489-96.

28. Henderson RA, Pocock SJ, Sharp SJ. Long-term results of RITA-1 trial: clinical and cost comparisons of coronary angioplasty and coronaryartery bypass grafting. Randomised Intervention Treatment of Angina. Lancet. 1998;352:1419-25. 